\title{
Multiple linear regression model for the assessment of bond strength in corroded and non-corroded steel bars in structural concrete
}

\author{
Miguel Prieto $\mathbb{D} \cdot$ Peter Tanner $\cdot$ Carmen Andrade
}

Received: 10 August 2015/ Accepted: 3 February 2016/Published online: 9 February 2016

(C) RILEM 2016

\begin{abstract}
With the growth and ageing of the stock of existing structures, structural assessment and retrofitting are fast acquiring a significant role in the construction industry. The benefits of upgrading existing reinforced concrete (RC) structures or extending their service life and of ensuring greater durability in designs for de novo construction have led to a need to include deterioration as a factor in structural safety models. Bond between reinforcing steel and concrete is of cardinal importance in this respect. The present paper proposes a unified formulation for assessing bond strength in corroded and non-corroded steel bars, and an associated model to accommodate the effect of transverse pressure where appropriate. The formulation is the result of applying multiple linear regression analysis to a database built from the findings of over 650 bond tests on corroded and non-corroded reinforcing steel reported in the literature. The data collected include a wide range of variables affecting
\end{abstract}

\footnotetext{
M. Prieto $(\bowtie) \cdot$ P. Tanner $\cdot$ C. Andrade Instituto de Ciencias de la Construcción Eduardo Torroja, Serrano Galvache, 4, 28033 Madrid, Spain

e-mail: mprietor@ietcc.csic.es URL: http://www.ietcc.csic.es

P. Tanner

e-mail: tannerp@ietcc.csic.es

URL: http://www.ietcc.csic.es

C. Andrade

e-mail: andrade@ietcc.csic.es

URL: http://www.ietcc.csic.es
}

bond strength, such as bar diameter, concrete compressive strength, concrete cover, anchorage length, confinement ratio and cross-sectional loss. A number of statistical criteria are used to compare the proposed formulation to the other bond strength assessment models, including the fib Model Code 2010 proposal for corroded steel bars. Further to the statistical tests conducted, the model proposed can be usefully applied to assess the structural safety of corroded RC members.

Keywords Existing structures - Assessment . Reinforced concrete $\cdot$ Corrosion - Bond strength · Multiple linear regression $\cdot$ Statistical characteristics

\section{Introduction}

Corrosion may affect the bond between reinforcing steel bars and concrete and hence the transfer of longitudinal stresses. Since the potential outcome of bond loss could be brittle structural behaviour, the verification of bond strength is of paramount importance in the assessment of corrosion-damaged existing structures.

The factors affecting bond behaviour in corroded steel include the weakening of concrete confinement due to concrete cover cracking and stirrup corrosion, the presence of corrosion products at the interface and, in ribbed bars, reduction of the bond index due to cross-sectional loss in the reinforcing steel bars. 
The importance of this issue has induced intense research. The findings reported in recent bond strength studies conducted on corroded steel diverge rather widely, however, due to differences in the corrosion procedures, test specimens and the variables analysed [1-3]. For that reason, no generalised bond strength formulas for corroded steel bars have been forthcoming.

In light of such differences, the present paper describes a statistical model for assessing bond strength generally applicable to corroded and noncorroded steel bars. The model was obtained by applying multiple linear regression analysis to a database drawn from the literature, covering over 650 bond tests on corroded and non-corroded reinforcing steel. The $95 \%$ prediction interval for estimating future bond strength values with the model is also given. In addition, a simplified version of the formula is introduced, along with a proposal that would make it possible to include the effect of transverse pressure where appropriate. Lastly, a number of statistical criteria are used to compare the

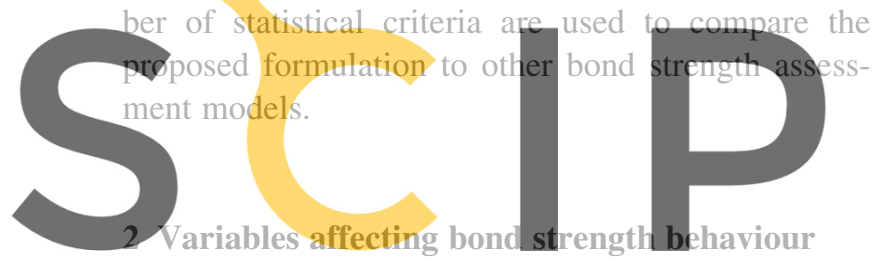
in corroded and non-corroded steel bars

Register for free at https//www.scipedia.com to Bond behaviour is affected by a wide variety of factors and parameters, some of which were selected as variables for the model proposed and are briefly described here. A detailed review of the literature on bonding can be found in $[4,5]$.

One such factor is concrete quality. Structural codes such as EN 1992-1-1 [6] and fib Model Code 2010 [7] (hereafter "MC2010") relate maximum bond strength to concrete compressive or tensile strength. Other technological characteristics also have a significant impact on concrete quality, however. A case in point is the position of the reinforcing steel during casting, which affects local bond-slip stiffness and maximum bond strength $[4,8]$. That effect is referred to in structural codes as bond condition quality, bar position during concreting in European standard EN 1992-1-1 [6] or bond condition in MC2010 [7].

Regarding concrete confinement CEB Bulletin 151 [4] published the findings of several experimental studies on short anchorage lengths, according to which bond strength increases with concrete confinement, namely with the concrete cover:bar diameter ratio $(c / \phi)$ ([9], inter alia). An experimental study conducted by Schenkel [10] likewise showed that for short anchorage lengths with a length:bar diameter ratio $\left(l_{b} / \phi\right)$ of 2 , maximum bond strength rose with $c / \phi$ ratios of up to 3.0. At higher values, the author observed no significant increase in bond strength.

Anchorage length is another factor that impacts bond strength, which has been conventionally assumed to be uniformly distributed along the embedded surface of the reinforcing steel. That assumption holds for short anchorage lengths with length:bar diameter ratios $\left(l_{b} / \phi\right)$ of up to 5 or 10 . The difference between local maximum and uniform bond strength rises with rising anchorage length, however [4]. Regarding anchorage length, Studies have been conducted on the effect of both short anchorage lengths on local bond behaviour and long lengths on overall behaviour [5]. Shima et al. [11] observed higher bond strength in short than in long anchorage lengths.



strength is strongly dependent on rib geometry and

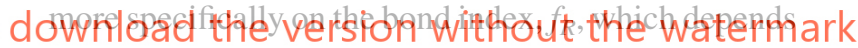
on the rib height, rib spacing and bar diameter $[8,13]$. As very few studies report the $f_{R}$ value, however, it was not included as a variable in the model proposed. Another parameter affecting both bond strength and the stiffness of the bond slip curve is bar diameter (size effect) $[8,12,13]$.

Bond strength is likewise modified by transverse reinforcement confinement. When bond failure is due to splitting, the presence of confining reinforcement improves bond strength [4]. As with concrete confinement, however, beyond a certain threshold value, increasing confinement with transverse reinforcement does not raise bond strength $[4,8]$.

Transverse pressure, as found in support areas in beams and slabs, affects bond strength by delaying the onset of splitting failure and raising frictional force at the bar/concrete interface [4, 14].

Finally, corrosion influences bond strength. As noted earlier, the findings on corrosion diverge fairly widely. As a general statement, for lower degrees of 
corrosion on the order of $5 \%$ (in the absence of any clear threshold in the literature) there is a different behaviour in bond strength compared to sound bars, including also the increase in bond strength $[5,15,16]$. At higher levels, above this threshold, bond strength declines significantly compared to bond strength in sound bars [5, 15, 16]. In [15] also it was found that confinement, in the form of stirrups or lateral pressure, minimises the adverse effect of corrosion on bond strength. Similar findings were also reported in [17].

All the above variables (except $f_{R}$, as noted) were built into the model proposed to determine bond strength in corroded and non-corroded reinforcing steel bars.

\section{Bond test database}

The bond strength assessment formula was derived from the results of 849 bond tests on corroded and noncorroded ribbed steel bars reported in the scientific literature ([2, 3, 12, 15, 17-29], among others). Given that natural corrosion is such accelerated in most of these b constant current density to the $\mu$ a slow process, it was
d tests by applying a
einforcing steel bars.
tests conducted at
$\mathrm{A} / \mathrm{cm}^{2}$, in the understanding that the values found for such rates would not

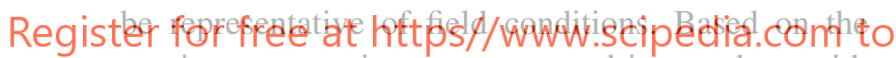
maximum corrosion rate measured in members with high chloride contamination (100-200 $\left.\mu \mathrm{A} / \mathrm{cm}^{2}\right)$ [30], that intensity criterion adopted here is also consistent with that considered in [31].

Only four of the tests remaining in the database after exclusion of the bond tests with current densities of over $200 \mu \mathrm{A} / \mathrm{cm}^{2}$ exhibited cross-sectional losses of over $20 \%$. These bond tests were likewise disregarded to maintain database balance. After these exclusions, the database ultimately analysed comprised 666 tests. In light of the paucity of results including transverse pressure, bond tests conducted by Prieto et al. and Rodriguez et al. [15, 17] in which this parameter was measured were used to derive a second formula (from the general formula) to take it into consideration.

The tests collected for this study and listed in [32] were as follows: 172 tests on unconfined sound steel bars, 122 on sound steel bars confined with transverse reinforcement, 165 on unconfined corroded steel bars and 207 on corroded steel bars confined with transverse reinforcement. By type, they included 66 beam tests, 75 pull-out tests, 501 eccentric pull-out tests (similar to the ones performed in the earlier study [15]) and 24 tests with other configurations.

Bond condition was regarded as good in 498 tests and as 'other' in the remaining 168, in keeping with the MC2010 [7] classification. Based on the anchorage length to bar diameter ratio $\left(l_{b} / \phi\right), 583$ tests involved "long anchorage" lengths, i.e., $l_{b} / \phi \geq 10$. While $l_{b} / \phi$ ratios of under 10 are not acceptable in design, they were included in the present analysis because the model is intended for use in the assessment of existing structures where the minimum value is often not attained. Table 1 gives the range of values found for some of the database variables studied in corroded and non-corroded steel bars.

Database notation is shown in Table 2.

\section{Model for bond assessment of corroded}

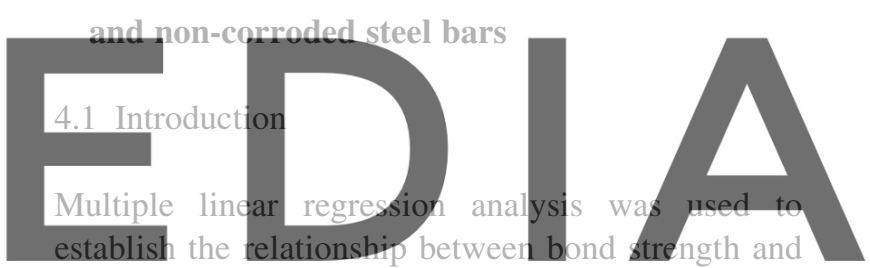

the variables described in Sect. 2. The results of the

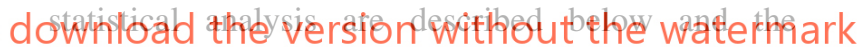
proposed model is presented, along with the $95 \%$ prediction interval for estimating future bond strength values. A simplified version of the proposal and a formulation to take the effect of transverse pressure into consideration are likewise discussed.

\subsection{Multiple linear regression model}

A summary of the multiple linear regression model used can be found in [33]. The notation for the response variable was changed in this article to concur with MC2010 [7].

The response variable used in the multiple regression model was mean or uniform bond strength $\left(f_{b, 0}\right)$, obtained by dividing the maximum bar force observed in the bond tests by the bar surface along the anchorage length, in turn divided by a function of concrete compressive strength $\left(f_{c}^{2 / 3}\right)$. The explanatory variables, based on the variables that affect bond strength as described in Sect. 2, were: 
Table 1 Range of values for variables in corroded and non-corroded steel bars



Non-corroded steel bars

$\begin{array}{lcclrrrrrr}\text { Min } & 9.5 & 16.4 & 40 & 3.57 & 0.0 & 0.0 & 0.50 & 0.0 & 0.0 \\ \text { Max } & 34.9 & 52.1 & 1117.6 & 40.00 & 139.7 & 10.5 & 10.00 & 0.0 & 0.2 \\ \text { Mean } & 16.4 & 37.5 & 230.9 & 13.4 & 35.9 & 2.2 & 2.7 & - & - \\ \text { SD } & 4.6 & 10.0 & 193.0 & 7.91 & 25.3 & 1.53 & 1.45 & - & - \\ \text { CoV } & 0.28 & 0.27 & 0.84 & 0.59 & 0.70 & 0.68 & 0.54 & - & -\end{array}$

Corroded steel bars

$\begin{array}{lccccccccc}\text { Min } & 10.0 & 18.6 & 129.0 & 10.5 & 12.0 & 1.0 & 1.5 & 0.2 & 0.0 \\ \text { Max } & 24.9 & 57.3 & 304.0 & 25.0 & 48.0 & 3.0 & 3.9 & 19.7 & 0.13 \\ \text { Mean } & 15.4 & 44.0 & 222.3 & 14.8 & 26.4 & 1.7 & 2.4 & 5.6 & - \\ \text { SD } & 3.35 & 11.16 & 47.86 & 3.59 & 7.95 & 0.54 & 0.64 & 3.96 & - \\ \text { CoV } & 0.22 & 0.25 & 0.22 & 0.24 & 0.30 & 0.31 & 0.27 & 0.71 & -\end{array}$
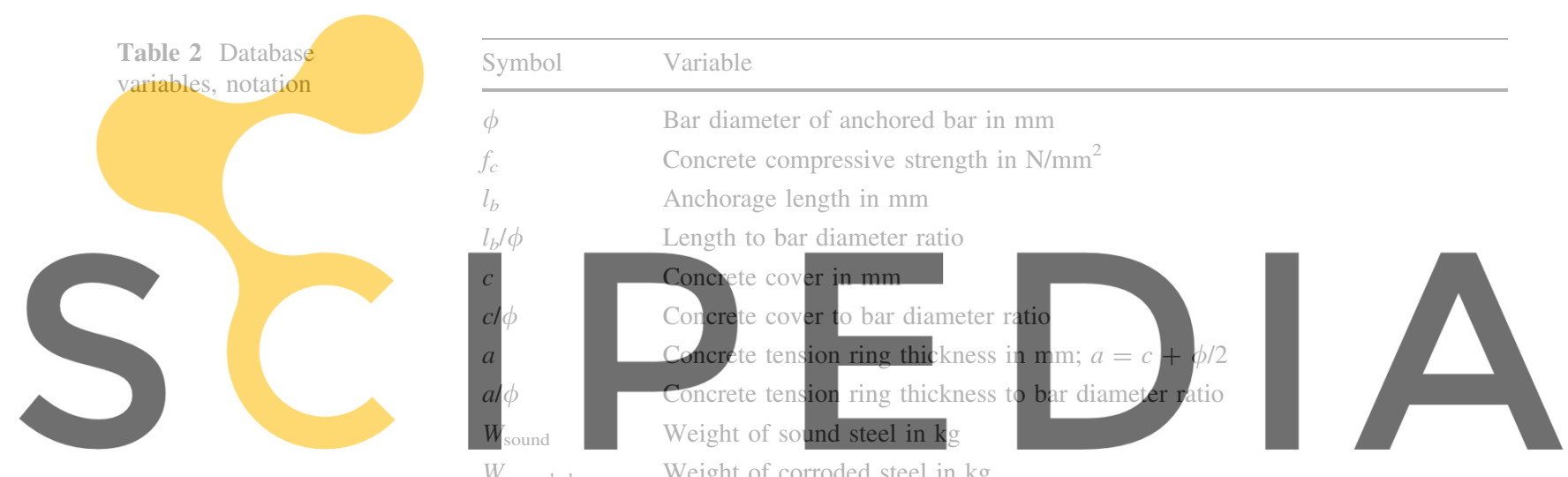

Weight of corroded steel in $\mathrm{kg}$


$n_{l} \quad$ Number of legs of confining reinforcement crossing a potential splitting failure

$A_{s t} \quad$ Cross sectional area of one leg of a confining bar in $\mathrm{mm}^{2}$

$n_{b} \quad$ Number of anchored bars

$s_{t} \quad$ Longitudinal spacing of confining reinforcement in $\mathrm{mm}$

$K_{t r} \quad$ Density of transverse reinforcement; $K_{t r}=n_{l} A_{s t} / n_{b} \phi s_{t}$

$\mathrm{CoV} \quad$ Coefficient of variation

- a categorical or dummy variable for bar bond condition, the two values being 'good' or 'any other bond condition' (POS)

- a categorical or dummy variable for confinement, the two values being 'none' or 'transverse reinforcement' (CONF)

- a categorical or dummy variable for the existence or otherwise of corrosion, with deterioration categories N1_COR $(0<\%$ Cor $\leq 5 \%)$ and N2_COR $(5<\%$ Cor $\leq 20 \%)$

- a continuous variable for the bar size effect (Ln $\left.\left((1 / \phi)^{2}+1\right)\right)$
- a continuous variable for the bar size effect ( Ln $\left.\left((1 / \phi)^{2}+1\right)\right)$

- a continuous variable for the effect of embedment length $\left(\operatorname{Ln}\left(\left(\phi / l_{b}\right)^{2}+1\right)\right)$

- a continuous variable for the effect of concrete brittleness with increasing concrete strength $\left(f_{c}\right)$ 40)

- a continuous variable for the effect of concrete confinement $\left(\operatorname{Ln}\left((a / \phi)^{4}+1\right)\right)$

- a continuous variable for the effect of stirrup confinement $\left(\operatorname{Ln}\left(K_{t r}^{2}+K_{t r}+1\right)\right)$ 
- a continuous variable for the effect of corrosioninduced deterioration in the concrete and the confinement stirrup $\left(\operatorname{Ln}\left((\% \text { Cor })^{2}+1\right)\right)$.

Most of the continuous variables were log-transformed to stabilise variance of the regression model.

The population defined for linear regression analysis was:

$$
\begin{aligned}
\operatorname{Ln}\left(f_{b, 0} / f_{c}^{2 / 3}+1\right)= & \beta_{1}+\beta_{2} \mathrm{POS}+\beta_{3} \mathrm{CONF} \\
& +\beta_{4} \mathrm{~N} 1 \_\mathrm{COR}+\beta_{5} \mathrm{~N} 2 \_\mathrm{COR} \\
& +\beta_{6} \operatorname{Ln}\left((1 / \phi)^{2}+1\right) \\
& +\beta_{7} \operatorname{Ln}\left(\left(\phi / l_{b}\right)^{2}+1\right)+\beta_{8} f_{c} / 40 \\
& +\beta_{9} \operatorname{Ln}\left((a / \phi)^{4}+1\right) \\
& +\beta_{10} \operatorname{Ln}\left(K_{t r}^{2}+K_{t r}+1\right) \\
& +\beta_{11} \operatorname{Ln}\left((\% \text { Cor })^{2}+1\right)+u(1)
\end{aligned}
$$

where $\beta_{j}$ symbolises the model parameters, with $j=1, \ldots, 11$ and $u$ is the disturbance term. The model


variable, as determined by the $t$ test. The procedure

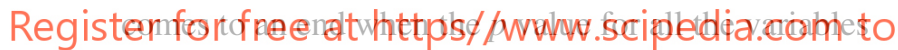
remaining in the model is less than or equal to the specified maximum, in this case 0.1. Applied to Eq. (1), backward elimination showed all the variables to be significant.

Unusual observations or outliers were identified as values with externally studentized residuals outside the range \pm 3.0 . Seventeen potential outliers or $2.55 \%$ of the database were found in the model proposed, i.e., a value within the $3 \%$ of outliers expected in multiple linear regression models.. After removal of these outliers, which reduced the database from $n=666$ to $n=649$, multiple linear regression analysis was repeated with model or Eq. (1).

The findings for model (1) are listed in Table 3. The adjusted coefficient of determination $\left(\bar{R}^{2}\right)$ of 0.866 means that the model explains the $86.60 \%$ of the variance of $\operatorname{Ln}\left(f_{b, 0} / f_{c}^{2 / 3}+1\right)$. The adjusted coefficient of determination was used in lieu of the standard $R^{2}$ to correct for the over-parameterisation of the latter.
The ANOVA (analysis of variance) findings for Eq. (1) are listed in Table 4. The value obtained for test statistic $F$ was 418.03 , while for an $\alpha$ value of 0.05 , the critical value of the distribution $\left(F_{10 ; 638 ; 0.05}\right)$ was 1.85. Given that the test statistic was much larger than the critical value, Eq. (1) was concluded to provide a statistically significant explanation for the differences in $\operatorname{Ln}\left(f_{b, 0} / f_{c}^{2 / 3}+1\right)$.

The following assumptions were verified for the multiple linear regression model proposed [35]:

- linearity

- homoscedasticity or constant variance

- normality

- independence of errors

- absence of multicollinearity.

Linearity of the model has been solved with logtransformation of some of the variables. White's test [35] and the diagram relating externally studentized residuals to predicted values confirmed homoscedasticity (see Fig. 1a). The respective curve also verified error inde-

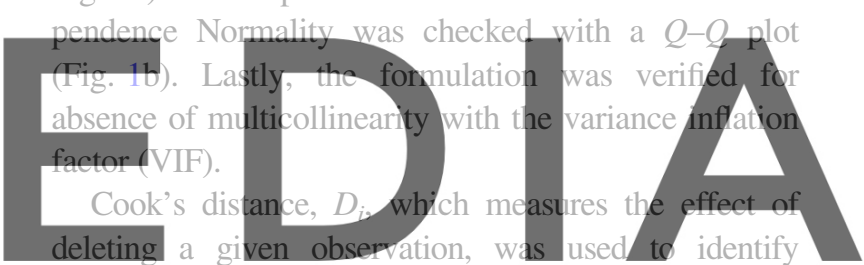

influential observations in the multiple linear regression

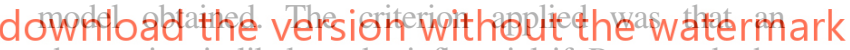
observation is likely to be influential if $D_{i}$ exceeds the median value in the Snedecor-Fischer distribution $\left(\mathrm{F}_{p, n-p}\right)$ where $n$ is the number of data items and $p$ the number of regression coefficients including the intercept. As the median of the $\mathrm{F}_{11 ; 638}$ distribution was 0.941 and the maximum value of $D_{i}$ was 0.042 , the linear regression model obtained was obviously free of influential observations.

In light of the foregoing, the formulation developed to assess bond strength in corroded and non-corroded steel bars was:

$$
\begin{aligned}
f_{b, 0}= & f_{c}^{2 / 3}\left(m\left(\frac{1}{\phi^{2}}+1\right)^{9.052}\left(\left(\frac{\phi}{l_{b}}\right)^{2}+1\right)^{8.13}\right. \\
& \times e^{-0.12 g^{\frac{f_{c}}{40}}}\left(\left(\frac{a}{\phi}\right)^{4}+1\right)^{0.058} \\
& \left.\times\left(K_{t r}^{2}+K_{t r}+1\right)^{0.498}\left(\% \operatorname{Cor}^{2}+1\right)^{-0.016}-1\right)
\end{aligned}
$$


Table 3 Summary of model parameters

\begin{tabular}{|c|c|c|c|c|}
\hline $\begin{array}{l}n \text { (number of } \\
\text { bond tests) }\end{array}$ & $R$ & $R^{2}$ & Adjusted $\bar{R}^{2}$ & $\begin{array}{l}s_{R} \text { standard error of } \\
\text { the estimate }\end{array}$ \\
\hline 649 & 0.931 & 0.868 & 0.866 & 0.069405 \\
\hline
\end{tabular}

Table 4 ANOVA (analysis of variance) for the regression significance

\begin{tabular}{|c|c|c|c|c|c|}
\hline Source of variance & $\begin{array}{l}\text { Sum of } \\
\text { squares }\end{array}$ & $\begin{array}{l}\text { Degrees } \\
\text { of freedom }\end{array}$ & Mean square & $F$ & sig. \\
\hline Regression & 20.137 & 10 & 2.014 & 418.03 & $\cong 0.000$ \\
\hline Residual & 3.073 & 638 & 0.005 & & \\
\hline Total & 23.210 & 648 & & & \\
\hline
\end{tabular}
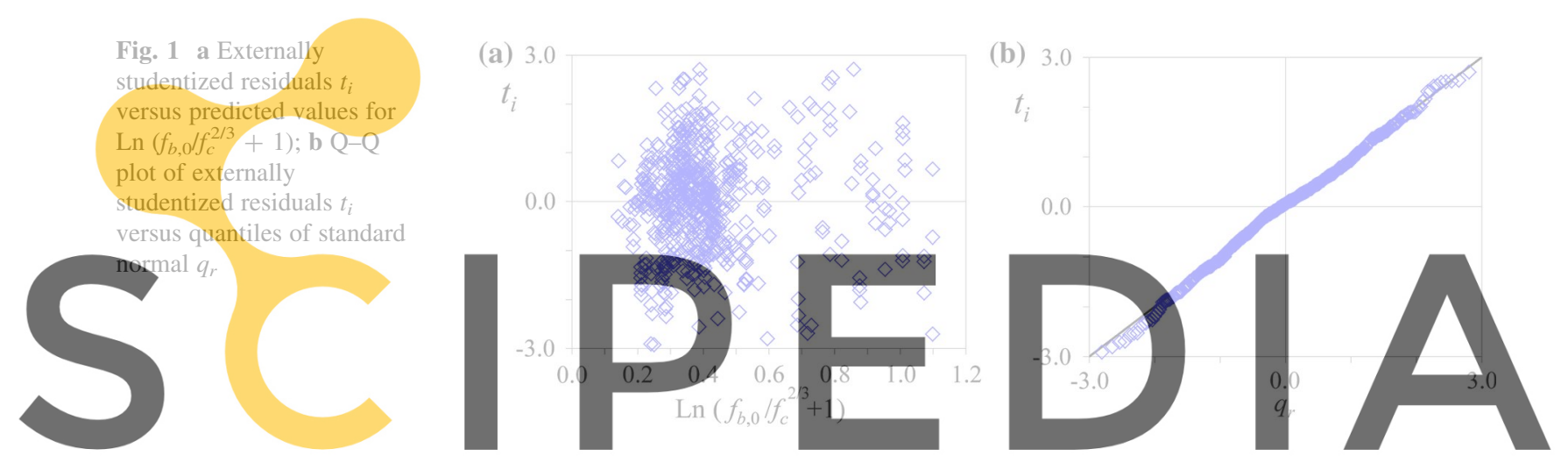

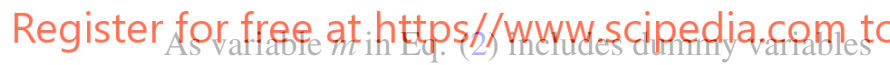
POS, CONF, N1_COR and N2_COR from Eq. (1), it encompasses the following bond strength-related parameters:

- bond condition (good; other)

- confinement (none; stirrups)

- corrosion category (no corrosion; $0<\%$ Cor $\leq 5 \% ; 5<\%$ Cor $\leq 20 \%)$.

Table 5 lists the values for variable $m$.

$\%$ Cor is the loss of cross-section along the bonded length and therefore accounts for uniform corrosion.

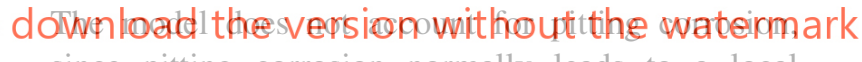
since pitting corrosion normally leads to a local reduction of the bar cross-section but does not affect the bond strength. Also note that as \% Cor is defined as the percentage of cross-sectional loss along the bonded length, it can be obtained by measuring the remaining cross-section along the bonded length with a calliper using the expression of Table 2 and the initial cross-section, and thus obviating the need to weigh the steel bars before and after corrosion.

The model can be used to predict future bond strength values $\left(\hat{f_{b}}\right)$, given specific values for the

Table 5 Values for $m$ by bond condition, confinement and corrosion

\begin{tabular}{llllll}
\hline & \multicolumn{2}{l}{ Good bond conditions } & & \multicolumn{2}{l}{ All other conditions } \\
\cline { 2 - 3 } & No Confinement & Confinement & & No Confinement & Confinement \\
\hline No corrosion & 1.275 & 1.324 & 1.235 & 1.283 \\
$0<\%$ Cor $\leq 5 \%$ & 1.245 & 1.293 & & 1.206 & 1.253 \\
$5 \% \%$ Cor $\leq 20 \%$ & 1.225 & 1.272 & & 1.187 & 1.233 \\
\hline
\end{tabular}


explanatory variables. The prediction interval is a range of values likely to contain the single value of the response variable when specific values for the explanatory variables are entered in the model. The $100(1-\alpha)$ percent prediction interval for a new observation at a particular point $\mathbf{x}_{\mathbf{0}}$ is the following:

$$
\begin{aligned}
\hat{f_{b}} & >\left(\mathrm{e}^{\operatorname{Ln}}\left(f_{b, 0} / f_{c}^{2 / 3}+1\right)-\left(t_{n-p-1, \alpha / 2}\right) s_{R} \sqrt{1+\mathbf{x}_{\mathbf{0}}^{\mathbf{T}}\left(\mathbf{X}^{\mathbf{T}} \mathbf{X}\right)^{-1} \mathbf{x}_{\mathbf{0}}}-1\right) f_{c}^{2 / 3} \\
& <\left(\mathrm{e}^{\operatorname{Ln}}\left(f_{b, 0} / f_{c}^{2 / 3}+1\right)+\left(t_{n-p-1, \alpha / 2}\right) s_{R} \sqrt{1+\mathbf{x}_{\mathbf{0}}^{\mathbf{T}}\left(\mathbf{X}^{\mathbf{T}} \mathbf{X}\right)^{-1} \mathbf{x}_{0}}-1\right) f_{c}^{2 / 3}
\end{aligned}
$$

where $t_{n-p-1, \alpha / 2}$ is the value of one tail of the cumulative Student's $t$ distribution with $n-p-1$ degrees of freedom and a significance of $\alpha / 2 ; s_{R}$ is the standard error for the estimate; $\mathbf{x}_{0}$ and $\mathbf{x}_{0}^{T}$ are, respectively, the matrix row and column of the values at which the model prediction is to be made; $\mathbf{X}$ is the $n \times p$ matrix of explanatory variables used to build the model, also called the design matrix; and $\mathbf{X}^{\mathbf{T}}$ is the transposed matrix for design matrix $\mathbf{X}$.

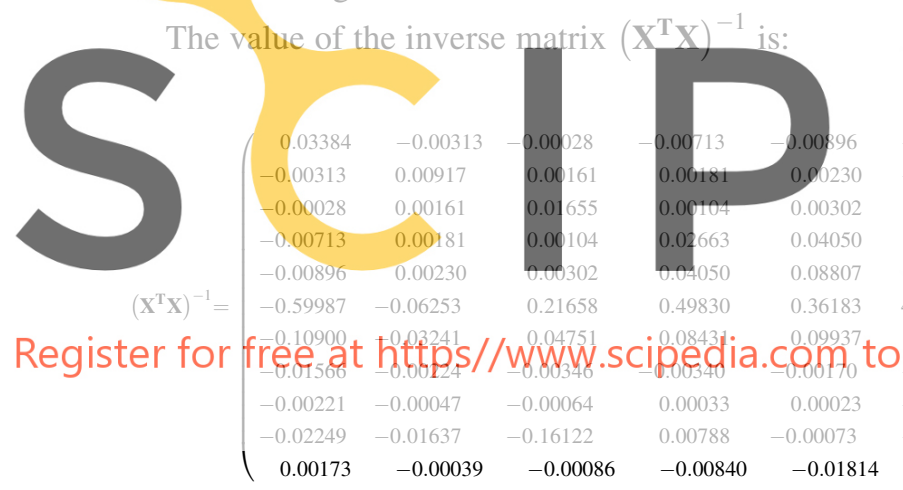

The $95 \%$ prediction interval for a future bond strength value $\left(\hat{f_{b}}\right)$ at point $\mathbf{x}_{\mathbf{0}}$ is:

$$
\begin{aligned}
\hat{f_{b}} & >\left(\mathrm{e}^{\operatorname{Ln}}\left(f_{b, 0} / f_{c}^{2 / 3}+1\right)-0.136 \sqrt{1+\mathbf{x}_{\mathbf{0}}^{\mathbf{T}}\left(\mathbf{X}^{\mathbf{T}} \mathbf{X}\right)^{-1} \mathbf{x}_{\mathbf{0}}}-1\right) f_{c}^{2 / 3} \\
& <\left(\mathrm{e}^{\operatorname{Ln}}\left(f_{b, 0} / f_{c}^{2 / 3}+1\right)+0.136 \sqrt{1+\mathbf{x}_{\mathbf{0}}^{\mathbf{T}}\left(\mathbf{X}^{\mathbf{T}} \mathbf{X}\right)^{-1} \mathbf{x}_{0}}-1\right) f_{c}^{2 / 3}
\end{aligned}
$$

See [32] for the $100(1-\alpha)$ per cent confidence interval for the mean value of the response variable at point $\mathrm{x}_{0}$ and a detailed discussion of the effect of each influencing variable and the degree of corrosion in formulation (2).

Some of the results are shortly summarised here. The formulation proposed (2) does not catch the increase of bond strength for very low corrosion levels. According to the analysis of all the influencing variables in bond strength, the high scatter observed in the experimental tests with corroded steel bars analysed for very low levels of corrosion did not reflect the increase of bond strength.

Furthermore, according to the results of formulation (2) and anchorage length to bar diameter ratio $\left(l_{b} / \phi\right)$, it has been noted that corrosion degrees up to $5 \%$ have a significant influence in bond strength loss, this influence is greater in long anchorage lengths $\left(l_{b} / \phi \geq 10\right)$ than in short anchorage lengths $\left(l_{b} / \phi\right.$ up to 10$)$. In the case of the thickness of the concrete tension ring to bar diameter ratio $(a / \phi)$, it has been noted that, according to the proposed formulation (2), corrosion degrees up to $5 \%$ causes a significant reduction of bond strength for $a / \phi<3.5$ ratios. For $a / \phi \geq 3.5$ ratios the influence of the degree of corrosion diminishes. In the case of concrete compressive strength and bond condition it has been observed that, according to the proposed formulation



emphasizes the adverse effect of the corrosion degree in bond strength and also that bond condition does not emphasize the adverse effect of the corrosion degree in bond strength.

\subsection{Simplified formulation}

Further to the MC2010 [7] level of approximation approach, a simplified level I formulation was derived from general formula (2):

$f_{b, 0}=\left(\eta_{1} \eta_{2} \eta_{3} \eta_{4} \eta_{5} \eta_{6}-1\right) f_{c}^{2 / 3}$

Expression (5) was obtained from the mean values of the coefficients used in formulation (2) for the database analysed. By way of example, coefficient $\eta_{1}$ 
Table 6 Values for coefficients $\eta_{1}, \eta_{2}, \eta_{3}, \eta_{4}, \eta_{5}$ and $\eta_{6}$

\begin{tabular}{ll}
\hline Parameter & Values \\
\hline Degree of corrosion & Non-corroded bars $\eta_{1}=1.24 ;$ \\
Bond condition & Corroded bars if $\%$ Cor $\leq 5 \% \eta_{1}=1.16$ otherwise $\eta_{1}=1.12$ \\
& Good bond conditions $\eta_{2}=1.03$ \\
Bar diameter & Otherwise $\eta_{2}=1.00$ \\
& $\phi \leq 10 \eta_{3}=1.10$ \\
Transverse reinforcement confinement & $10<\phi \leq 20 \eta_{3}=1.04$ \\
& $\phi>20 \eta_{3}=1.02$ \\
Concrete cover & No confinement $\eta_{4}=1.00$ \\
& Confinement with $K_{t r} \leq 0.05 \eta_{4}=1.04$ \\
& Confinement with $K_{t r}>0.05 \eta_{4}=1.06$ \\
& $a / \phi \leq 1.5 \eta_{5}=0.97$ \\
Anchorage length & $1.5<a / \phi \leq 3.5 \eta_{5}=1.06$ \\
& $a / \phi>3.5 \eta_{5}=1.26$ \\
& $l_{b} / \phi \leq 10 \eta_{6}=1.50$ \\
& $l_{b} / \phi>10 \eta_{6}=1.04$
\end{tabular}

encompasses categorical variables N1_COR,

N2_COR and continuous variable \% Cor. The values

of eoefficient $\eta$ for the simplified formulation are histed

in Table 6.

4.4 Effect of

Due to the paucity of bond tests on sound and corroded


pressure was one of the factors consldered, only 15 bond tests could be collected for this study. Of the 11 involving corroded steel bars, four were conducted in a prior study by the authors [15]. This variable was consequently not addressed in the statistical analysis

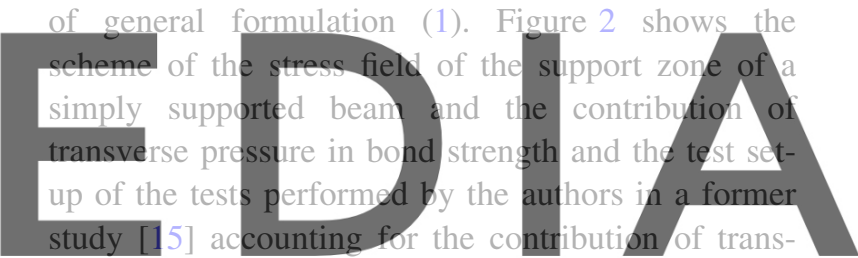

verse pressure in bond strength.

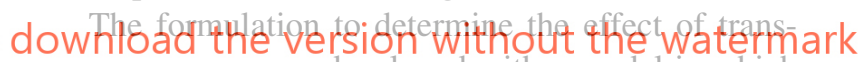

verse pressure was developed with a model in which

bond strength $\left(f_{b}\right)$ is expressed as the sum of the contribution to strength found with proposed formulation (2) $\left(f_{b, 0}\right.$ : a function of concrete strength, degree

(a)

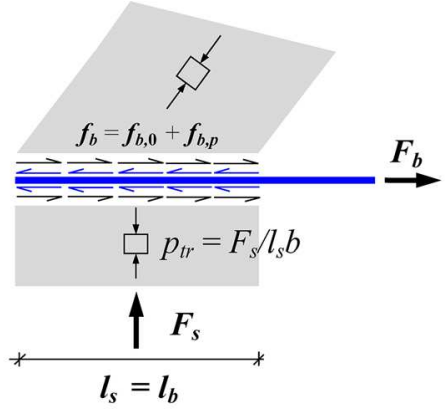

(b)

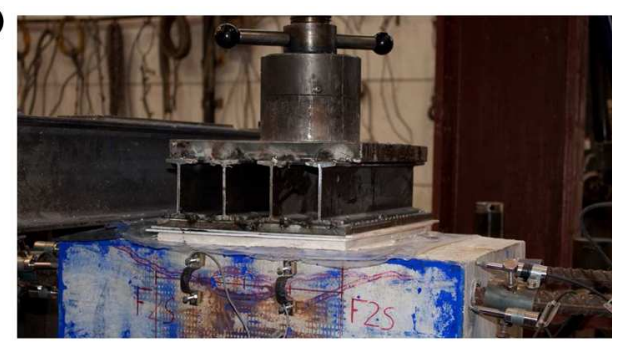

$\boldsymbol{l}_{\boldsymbol{s}}=\boldsymbol{l}_{\boldsymbol{b}}=$ support length $=$ anchorage length

$\boldsymbol{b}=$ support width

Fig. 2 a Stress field of the support zone of a simply supported beam and the contribution of transverse pressure in bond strength; $\mathbf{b}$ Setup of the test performed accounting for the contribution of transverse pressure performed by the authors in a former study [15] 
of corrosion, geometry, bar size and confinement) and the contribution of transverse pressure $\left(f_{b, p}\right)$.

The first step consisted in predicting the bond strength with formulation (2) and using the result to compute the contribution of transverse pressure $\left(f_{b, p}\right)$ by subtracting the value calculated for $f_{b, 0}$ from experimental bond strength $\left(f_{b, \text { exp }}\right)$.

$f_{b, p}=f_{b, \exp }-f_{b, 0}$

That was followed by regression analysis to determine the relationships among the contribution of transverse pressure, a function of that pressure $\left(p_{t r}\right)$ and concrete compressive strength $\left(f_{c}\right)$. The contribution of transverse pressure was found to be:

$$
f_{b, p}=2.82-1.96 \operatorname{Ln}\left(p_{t r} /\left(0.1 f_{c}\right)\right)
$$

where $p_{t r}$ is the mean stress in the concrete (orthogonal to the bar axis) induced by the support obtained dividing the force over the area of the support (N/ $\mathrm{mm}^{2}$ ), see Fig. 2.

Finally, if transverse pressure is present, as is the

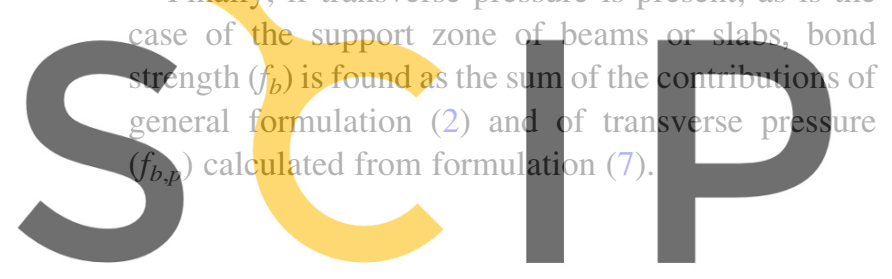

\section{Registê Pigfulssiee at https//www.scipedia.com to}

\subsection{Review of existing models}

The Contecvet manual [36] contains a proposal for assessing corroded steel bond strength based on a study by Rodriguez et al. [17]. Drawing on the data from an extensive experimental campaign, these authors developed two formulations, one for unconfined corroded steel and the other for corroded steel confined with transverse reinforcement. The following equations were used to assess mean bond strength in unconfined and confined corroded steel, respectively:

$f_{b}=3.00-4.76 P_{x}$

$f_{b}=5.25-2.72 P_{x}$

where $P_{x}$ in $\mathrm{mm}$ is mean corrosion penetration.

No explicit formulation is given in MC2010 [7] for assessing bond strength in corroded steel. Rather, strength is classified by bar type (ribbed or plain) and confinement (with or without). The residual capacity $\left(f_{b d}\right)$ in corroded steel further to model code criteria, i.e., corrosion penetration, $P_{x}$, or equivalent surface cracking, is reproduced in Table 7 below.

According to MC2010 [7], basic bond strength is calculated as:

$f_{b d, 0}=\eta_{1} \eta_{2} \eta_{3} \eta_{4}\left(f_{c} / 25\right)^{0.5}$

where $\eta_{1}, \eta_{2}, \eta_{3}$ and $\eta_{4}$ are coefficients respectively denoting bar type, bond condition, bar diameter and characteristic yield strength. Neither partial factor $\gamma_{c}$ nor the characteristic value of $f_{c}$ is included in Eq. (10).

Equation (10) was derived from the following general equation set out in MC2010 [7] for reinforcement stress:
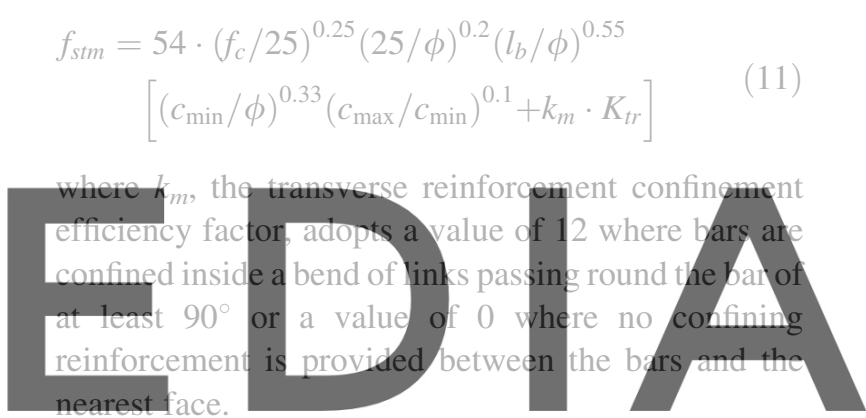

In MC2010 [7], bond strength $\left(f_{b}\right)$ is obtained by

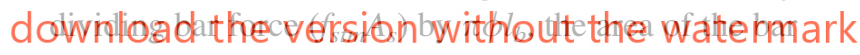
in which reinforcement stress $\left(f_{\text {stm }}\right)$ develops.

The following criteria given in MC2010 [7] were used to derive Eq. (10) from (11): mean bond strength was replaced by characteristic strength, minimum concrete cover and detailing were applied and indexes and coefficients were rounded up or down, as appropriate.

In this study, the following assumptions were also made to obtain bond strength predictions:

- Bond strength for corroded steel was obtained with the values in Table 7 and Eqs. (10) and (11) for sound steel. Equation (11) was simplified by taking the ratio between maximum and minimum cover $\left(c_{\max } / c_{\min }\right)$ to be 1.0 .

- Given the mean corrosion penetration, $P_{x}$, found for the corroded steel, the percentages in Table 7 were applied to the values obtained with Eqs. (10) and (11). Since Table 7 gives only three $P_{x}$ values, the reduction of bond strength was applied 
Table 7 Residual bond capacity for corroded steel in MC2010 [7]

\begin{tabular}{|c|c|c|c|c|c|c|}
\hline \multirow{4}{*}{$\begin{array}{l}\text { Corrosion penetration, } \\
P_{x}(\mathrm{~mm})\end{array}$} & \multirow{4}{*}{$\begin{array}{l}\text { Equivalent surface } \\
\text { crack }(\mathrm{mm})\end{array}$} & \multirow[t]{4}{*}{ Confinement } & \multicolumn{4}{|c|}{ Residual capacity ( $\%$ of $f_{b d}$ ) } \\
\hline & & & \multicolumn{4}{|c|}{ Bar type } \\
\hline & & & \multicolumn{2}{|l|}{ Ribbed } & \multicolumn{2}{|l|}{ Plain } \\
\hline & & & Upper & Lower & Upper & Lower \\
\hline 0.05 & $0.20-0.40$ & No stirrups & 70 & 50 & 90 & 70 \\
\hline 0.10 & $0.40-0.80$ & & 50 & 40 & 60 & 50 \\
\hline 0.25 & $1.00-2.00$ & & 40 & 25 & 40 & 30 \\
\hline 0.05 & $0.20-0.40$ & Stirrups & 100 & 95 & 100 & 95 \\
\hline 0.10 & $0.40-0.80$ & & 80 & 70 & 100 & 95 \\
\hline 0.25 & $1.00-2.00$ & & 75 & 60 & 100 & 90 \\
\hline
\end{tabular}

stepwise. When corrosion penetration was higher than the $0.25 \mathrm{~mm}$ listed in Table 7 , that maximum was used. Pursuant to this procedure, upper and lower limits were calculated for Eqs. (10) and (11). 5.2 Statistical criteria

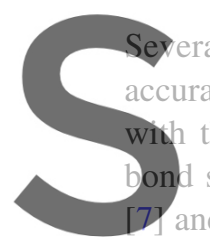
eral statistical criteria w ccuracy of the bond strengt the proposed model strength assessments deli used
predictio
descril to compare the
actions obtained
accuracy of the
by the MC2010
bed in Sect. 5.1. Predicted residual sum of squares (PRESS), one of

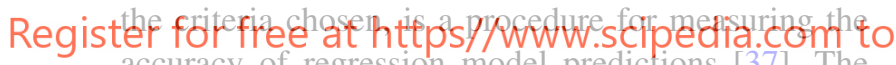
accuracy of regression model predictions [37]. The PRESS statistic is:

$$
\begin{aligned}
\text { PRESS } & =\sum_{i=1}^{n}\left(f_{b, \exp , i}-\hat{f}_{b(i)}\right)^{2}=\sum_{i=1}^{n} e_{(i)}^{2} \\
& =\sum_{i=1}^{n}\left(e_{i} /\left(1-h_{i i}\right)\right)^{2}
\end{aligned}
$$

where $f_{b, \exp }$ is the observed experimental bond strength value, $f_{b(i)}$ the predicted value of the bond strength for the $i$ th response based on all except the $i$ th observation, $e_{(i)}$ the deleted or PRESS residual and $h_{i i}$ the weight of each observation in the regression model.

As a rule, models with small PRESS values are preferred over those with large values. Good criteria for comparing models can also be obtained by decomposing the PRESS statistic with, for instance, the mean squared error of prediction, MSEP [37]:

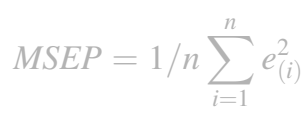

(13)

The predictive residual mean (PRM), the estimate of the systematic error in model predictions, is related to the centroid of the scatter plot, defined by the mean value of bond strength of the experimental tests, $\bar{f}_{b \text {.exp }}$,

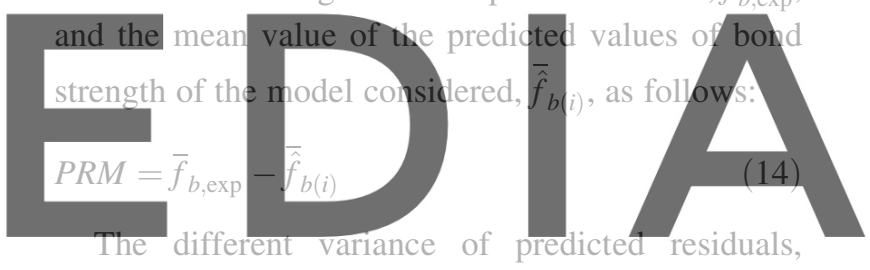

DVPR, furnishes information on the orthogonal

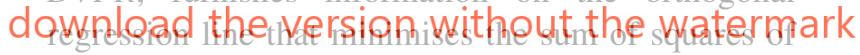

the Euclidean distances to the regression line. Positive DVPR values denote an experimental variance higher than the variance predicted by the model:

$D V P R=s_{f_{b, \mathrm{exp}}}-s_{\hat{f}_{(i)}}$

where $s_{f_{b, \text { exp }}}$ is the standard deviation of the experimental values of bond strength and $s_{\hat{f}_{b(i)}}$ is the standard deviation of the predicted values of bond strength.

Information on the scatter on each side of the orthogonal regression line is obtained with the incomplete correlation predictive residual, ICPR:

$I C P R=\sqrt{2(1-r) s_{f_{b, \exp }} s_{\hat{f}_{b(i)}}}$

where $r$ is the correlation coefficient.

The orthogonal regression line and its slope can be obtained from the following expressions [37]: 


$$
\begin{aligned}
\tan (\theta)= & \left(s_{f_{b, \text { exp }}}^{2}-s_{\hat{f}_{b(i)}}\right) /\left(2 r s_{f_{b, \text { exp }}} s_{\hat{f}_{b(i)}}\right) \\
& \pm \sqrt{\left(\left(s_{f_{b, \text { exp }}}^{2}-s_{\hat{f}_{b(i)}}\right) / 2 r s_{f_{b, \text { exp }}} s_{\hat{f}_{b(i)}}\right)^{2}+1}
\end{aligned}
$$

$f_{b, \exp }-\bar{f}_{b, \exp }=\tan (\theta)\left(f_{b(i)}-\overline{\hat{f}}_{b(i)}\right)$

The intersection between the orthogonal regression line and the first quadrant bisector on the experimental-predicted graph defines the areas where, on average, the model can (and cannot) be safely used.

Another criterion for establishing model accuracy is the $M$ ratio between the experimental value and the model estimate. The $m_{i}$ ratio for the $i$ th observation is obtained by dividing the experimental value $\left(f_{b \text {,exp }}\right)$ by the predicted value $\left(f_{b(i)}\right)$ :

$m_{i}=f_{b, \exp } / f_{b(i)}$

Decomposing the PRESS statistic yields useful quantitative information on the origin of model variability, while the $M$ ratio provides the adjustment of the model and also the variability of the ratio between the experimental value and the model estimate.

\subsection{Comparison}

Statistical models may be reliably validated by verifying their results against an independent sample [35]. Unfortunately, this procedure is not normally an option due to a paucity of data. An alternative and likewise robust procedure for model validation consists in choosing a random sample of the data used to build the model. Two such samples were used here: in one the bond tests involved corroded and in the other sound steel. All the data were used for the statistical validation, including the outliers disregarded in the development of formulation (2). The sole exception was one of the tests conducted in the absence of a concrete cover that could not consequently be assessed with Eq. (11) taken from MC2010 [7], thus no concrete cover was present in this bond test. In the analysis conducted here, experimental bond strength was compared to model prediction results using the statistical criteria described in Sect. 5.2. A sample of 293 bond tests on sound steel was used to compare proposed model (2) to Eq. (11) taken from MC2010
[7], although the model proposed is intended primarily to reliably predict bond strength in corroded steel bars. The model statistics are summarised in Table 8 .

Figure $3 \mathrm{a}, \mathrm{b}$ compare the experimental bond strength for sound steel bars respectively to the values predicted with proposed model (2) and Eq. (11) taken from MC2010 [7].

The $M$ ratio for the two models showed that experimental bond strength was slightly underestimated by proposed model (2) and slightly overestimated by Eq. (11) taken from MC2010 [7]. The mean $M$ ratio found for Eq. (11) was consistent with the value obtained by [14], although the coefficient of variation $(\mathrm{CoV})$ was slightly higher due to the wider range of values in the database used in this study. For sound bars and the database used, model (2) yielded a fairly low $\mathrm{CoV}$, given the wide variety of parameters that affect bond strength.

According to the PRESS statistic, proposed formulation (2) had greater predictive power than Eq. (11) taken from MC2010 [7] for sound bars in the database analysed. The mean squared predictive error (MSEP) was nearly four times higher in Eq. (11) taken from MC2010 [7] than in proposed model (2).

Further to the systematic prediction error found with the PRM statistic, on average, the results delivered by model (2) were positioned on the side of safety. This is illustrated in Fig. 3a, where the centroid $(G)$ of the scatterplot, defined by the mean experimental bond strength $\left(\bar{f}_{b, \exp }\right)$ and the mean bond strength predicted by the model $\left(\overline{\hat{f}}_{b(i)}\right)$ of all the test analysed, is located above the bisecting line. In contrast, the negative value of this statistic found for the MC2010 [7] model was an indication that on average bond strength was overestimated. In this case, the diagram centroid $(\mathrm{G})$, was below the bisecting line (see Fig. 2b).

The cut-off point ( $\mathrm{E}$ in Fig. 3a, b) is the intersection between the orthogonal regression line and the first quadrant bisector on the experimental-predicted values graph. It defines the areas where the model yields safe results or otherwise, on average, depending on the slope of the orthogonal regression line. The cut-off values were 6.99 in formulation (2) and 9.14 in Eq. (11) taken from MC2010 [7]. In other words, bond strengths upward of those values predicted with 
Table 8 Statistical parameters for bond tests on sound bars assessed using proposed model (2) and Eq. (11) taken from MC2010 [7]

\begin{tabular}{lcccccccccc}
\hline Model & $n$ & PRESS & MSEP & PRM & DVPR & ICPR & $\begin{array}{l}\text { Cut-off } \\
\text { point }\end{array}$ & $\mu_{M}$ & $s_{\underline{M}}$ & CoV \\
\hline Model proposed Eq. (2) & \multirow{2}{*}{293} & 1308.18 & 4.47 & 0.11 & 0.37 & 2.08 & 6.99 & 1.02 & 0.21 & 0.21 \\
Equation (11) from MC2010 [7] & & 4522.56 & 15.44 & -0.33 & 1.67 & 3.54 & 9.14 & 0.97 & 0.38 & 0.40 \\
\hline
\end{tabular}

Fig. 3 Experimental bond strength in sound steel bars versus values predicted by: a proposed formulation (2); b Eq. (11) taken from MC2010 [7] (adapted from [33])


Eqs. (2) or (11), respectively, will lie on the side of safety.

Bond tests conducted on corroded steel, 372 in all, were also analysed. Here the proposed formulation (2) was compared to the Contecvet [36] model and the upper and lower limits found for Eqs. (10) and (11) taken from MC2010 [7]. The statistical parameters for the models are listed in Table 9.

Experimental corroded steel bar bond strength is plotted against the values predicted with proposed formulation (2), the Contecvet [36] model and the upper and lower limits found with Eq. (11) taken from MC2010 [7] in Fig. 4a-d, respectively.

Judging from the mean $M$ ratio (1.0), model (2) yielded accurate predictions for bond strength in corroded steel. As observed for sound bars, the CoV for this model was fairly low given the number of variables addressed, in addition in this case to the effects of corrosion. Further to the $M$ ratio data in Table 9, the upper limit for Eq. (11) taken from MC2010 [7] delivered the second-best performance, although with a slightly conservative bias and a $\mathrm{CoV}$ that nearly doubled the CoV for proposed model (2). All the other models, particularly the upper and lower limits for Eq. (10) taken from MC2010 [7], proved to be on average overly conservative.

The lowest value for the PRESS statistic, by far, was found for proposed model (2), followed in ascending order by the lower and upper limits for the MC2010 [7] (Eq. (11) here). Proposed model (2) also

Table 9 Statistical parameters for the proposed (2), Contecvet [36] (Eqs. (8) and (9) here) and MC2010 [7] (Eqs. (10) and (11) here) models for predicting bond strength in corroded steel bars

\begin{tabular}{|c|c|c|c|c|c|c|c|c|c|c|}
\hline Model & $n$ & PRESS & $M S E P$ & $P R M$ & $D V P R$ & $I C P R$ & Cut-off point & $\mu_{M}$ & $s_{M}$ & $\mathrm{CoV}$ \\
\hline Model proposed Eq. (2) & 372 & 512.68 & 1.38 & 0.034 & 0.43 & 1.09 & 4.74 & 1.00 & 0.27 & 0.27 \\
\hline Contecvet [36] Eq. (8) and (9) & & 1808.66 & 4.86 & 1.38 & 0.47 & 1.55 & 0.79 & 2.38 & 14.90 & 6.27 \\
\hline Upper limit Eq. (10) MC2010 [7] & & 5849.40 & 15.72 & 3.56 & 1.51 & 0.68 & 0.36 & 3.86 & 1.79 & 0.46 \\
\hline Lower limit Eq. (10) MC2010 [7] & & 6731.21 & 18.10 & 3.87 & 1.54 & 0.68 & 0.07 & 5.34 & 3.11 & 0.58 \\
\hline Upper limit Eq. (11) MC2010 [7] & & 1599.52 & 4.30 & -0.56 & -1.06 & 1.67 & 4.07 & 1.02 & 0.47 & 0.46 \\
\hline Lower limit Eq. (11) MC2010 [7] & & 1456.08 & 3.91 & 0.620 & -0.75 & 1.67 & 6.11 & 1.43 & 0.80 & 0.56 \\
\hline
\end{tabular}


Fig. 4 Experimental bond strength in corroded steel bars versus values predicted by: a proposed formulation (2); b the Contecvet [36] (Eqs. (8) and (9) here); c the upper limit for the MC2010 model [7] (Eq. (11) here); d the lower limit for the MC2010 model [7] (Eq. (11) here) (adapted from [33])
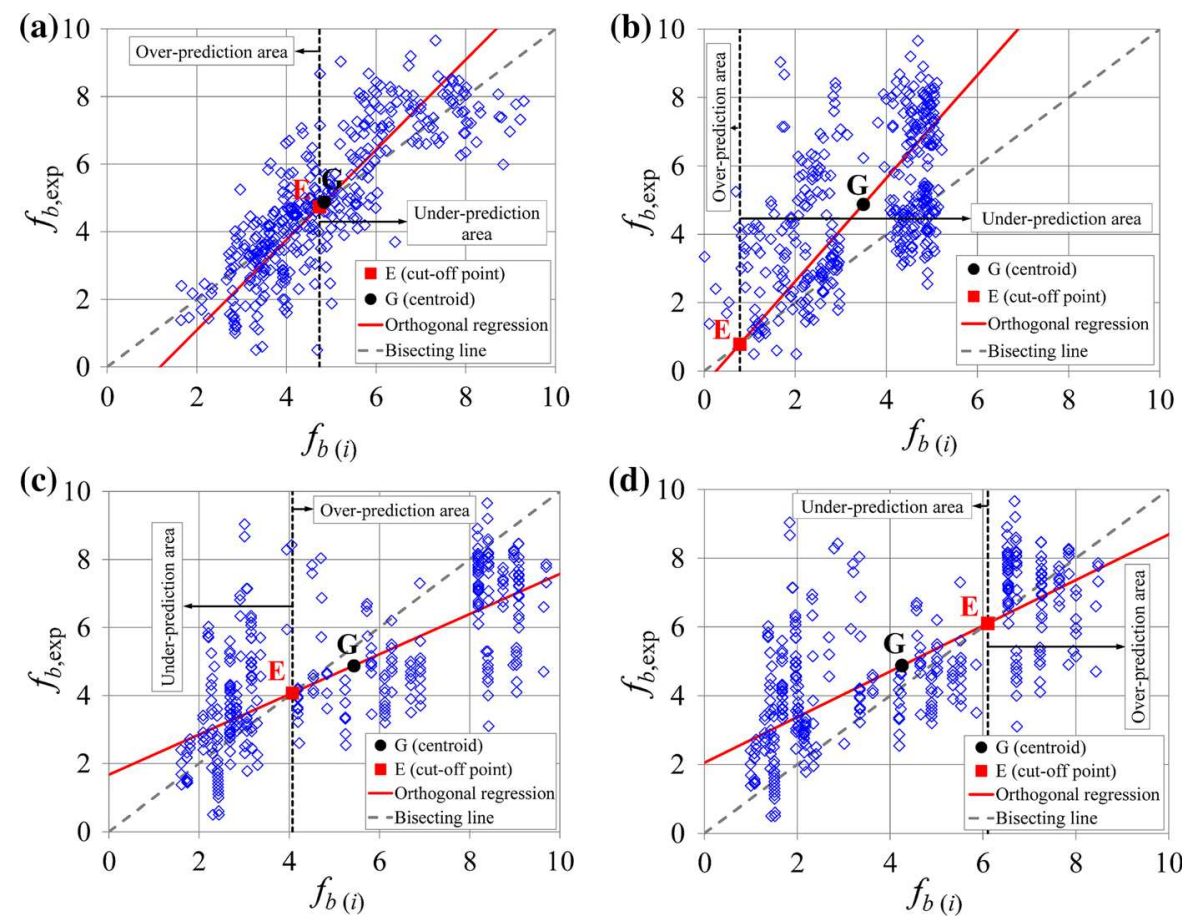

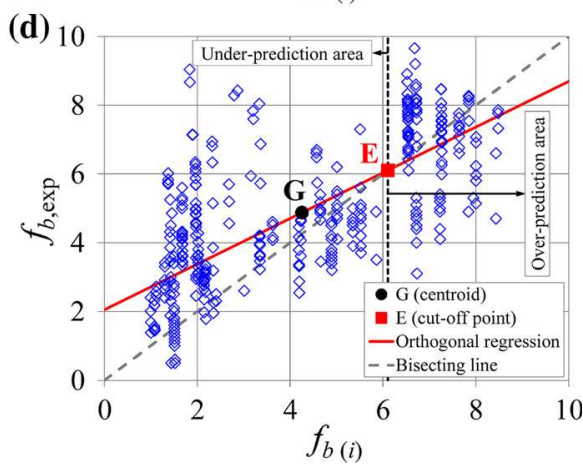

featured the lowest mean squared predictive error (MSEP) followed by the lower and upper limits for the MC2010 [7] (Eq. (10) here) and the Contecvet [36] models in that order. The PRM statistic calculated for proposed model (2) was the lowest of the positive values observed, indicating that the results were on the side of safety on average. The next lowest was the lower limit for the MC2010 [7] (Eq. (11)) and Contecvet [36] models. The negative PRM found for the upper limit for MC2010 [7] (Eq. (11)) means that the model overestimated bond strength on average.

As the cut-off point ( $\mathrm{E}$ in Fig. 4) in proposed formulation (2) was 4.7, bond strengths predicted with the model upward of that value would lie on the side of safety. The cut-off points for the upper and lower limits in the MC2010 [7] model (Eq. (11)) were 4.07 and 6.11, respectively. Given the slope of the orthogonal regression line, however, predicted bond strengths higher than those values would not lie on the side of safety.

In addition to the statistical parameters analysed, the $M$ ratio between the bond strength experimental values and the values predicted with proposed formulation (2) for the bond test of corroded steel bars is plotted against the different influencing variables, $\%$ Cor, length to bar diameter ratio $\left(l_{b} / \phi\right)$, concrete tension ring thickness to bar diameter ratio $(a / \phi)$, bar diameter $(\phi)$, concrete compressive strength $\left(f_{c}\right)$ and stirrup confinement $\left(K_{t r}\right)$ in Fig. 5a-f, respectively.

The analysis of the proposed formulation (2) with the experimental data collected shows no significant statistical correlation between the $M$ ratio and any of the basic variables influencing bond strength as can be seen in Fig. 5a-f.

Further to the statistical parameters analysed and the analysis of the model against the variables influencing bond strength, then, the model proposed assessed bond strength in sound and corroded steel bars reasonably well.

\section{Conclusions}

The present paper proposes a formulation for assessing bond strength in sound and corroded steel bars, developed by applying multiple linear regression to a database containing the results of over 650 bond tests. The tests were drawn from a prior study of the authors [15] and the literature. The data collected for the study covered a wide range of variables affecting bond strength, such as bar diameter, concrete compressive strength, concrete cover, anchorage length, confinement ratio and corrosion-induced cross-sectional loss. The prediction intervals for this new bond strength 
Fig. $5 M$ ratio of the proposed formulation (2) for the corroded steel bars versus influencing variables: a \% Cor, b length to bar diameter ratio $\left(l_{b} / \phi\right)$, c concrete tension ring thickness to bar diameter ratio $(a / \phi), \mathbf{d}$ bar diameter $(\phi)$, e concrete compressive strength $\left(f_{c}\right), \mathbf{f}$ stirrup confinement $\left(K_{t r}\right)$


formulation are also given. An additional formulation is introduced to accommodate the transverse pressure present in support areas in beams and slabs.

A number of relevant statistical criteria were used to validate proposed model (2) and compare it to other models for assessing bond strength in corroded steel, such as the Contecvet [36] and MC2010 [7] models. All the statistical tests showed that the model proposed delivers reasonably good results. Its predictions afforded a closer fit to the experimental results and were less scattered than in other models used to assess bond strength in corroded steel. Furthermore, the analysis of the experimental data revealed no significant statistical correlation between the proposed model (2) and any of the basic variables influencing bond strength. Those findings are an indication of its utility to assess the safety of steel-concrete bonding in reinforced concrete members. Moreover, the empirical formulation proposed in this paper is expected to serve as a basis to derive rational physical models of the relevant physical phenomena regarding bond strength with corroded steel bars.

\section{References}

1. Coccia S, Imperatore S, Rinaldi Z (2014) Influence of corrosion on the bond strength of steel rebars in concrete. Mater Struct. doi:10.1617/s11527-014-0518-x

2. Fischer C (2012) Influences of reinforcement corrosion on bond between steel and concrete (in German). Ph.D. Thesis, Stuttgart University

3. Yalciner H, Eren O, Sensoy S (2012) An experimental study on the bond strength between reinforcement bars and concrete as a function of concrete cover, strength and corrosion level. Cem Concr Res 42:643-655. doi:10.1016/j.cemconres. 2012.01.003

4. CEB (1982) Bulletin d'Information 151. Bond action and bond behaviour of reinforcement. CEB, Paris

5. FIB (2000) Fib Bulletin 10. Bond of reinforcement in concrete. FIB (International federation for structural concrete), Lausanne 
6. CEN (2004) Eurocode 2: design of concrete structures-part 1-1: general rules and rules for buildings. CEN, Brussels

7. FIB (2013) Fib Model Code for concrete structures 2010. FIB (International Federation of Structural Concrete), Lausanne

8. FIB (2014) Fib Bulletin 72. Bond and anchorage of embedded reinforcement: background to the fib Model Code for concrete structures 2010. FIB (International federation for structural concrete), Lausanne

9. Tepfers R (1973) A theory of bond applied to overlapped tensile reinforcement splices for deformed bars. Ph.D., Chalmers University of Technology

10. Schenkel M (1998) Bond behaviour of reinforcement with reduced Concrete Cover (Zum Verbundverhalten von Bewehrung bei kleiner Betondeckung-in German). Ph.D., Swiss Federal Institute of Technology Zürich (ETHZ)

11. Shima H, Chou LL, Okamura H (1987) Bond characteristics in post-yield range of deformed bars. Proc Jpn Soc Civ Eng (JSCE) 6:79-94

12. Mathey RG, Watstein D (1961) Investigation of bond in beam and pull-out specimens with high yield-strength deformed bars. J Am Concr Inst 57:1071-1090

13. Metelli G, Plizzari GA (2014) Influence of the relative rib area on bond behaviour. Mag Concr Res 66:277-294. doi:10.1680/macr.13.00198

14. Cairns J (2015) Bond and anchorage of embedded steel reinforcement in fib Model Code 2010. Struct Concr 16:45-55. doi:10.1002/suco.201400043

15. Prieto M, Tanner P, Andrade C, Fernandez Ruiz M (2013) Experimental and numerical study of bond response in structural concrete with corroded steel bars. Paper presented at the IABSE Conference on Assessment, Upgrading and refurbishment of Infrastructures, Rotterdam

16. Tondolo F (2015) Bond behaviour with reinforcement corrosion. Constr Build Mater 93:926-932. doi:10.1016/j. conbuildmat.2015.05.067

17. Rodriguez J, Ortega LM, Casal J, Díez JM (1995) The residual service life of reinforced concrete structures. Task 3.2. Relation between corrosion and bond deterioration. Geocisa, Madrid

18. Al-Sulaimani GJ, Kaleemullah M, Basunbul IA, Rasheeduzzafar (1990) Influence of corrosion and cracking on bond behavior and strength of reinforced concrete members. ACI Struct J 87:220-231

19. Almusallam AA, Al-Gahtani AS, Aziz AR, Rasheeduzzafar (1996) Effect of reinforcement corrosion on bond strength. Constr Build Mater 10:123-129. doi:10.1016/09500618(95)00077-1

20. Alonso MDG (1995) Aportaciones al comportamiento resistente de estructuras de hormigón armado afectadas por la corrosión de sus armaduras (Contributions to the resistance behaviour of reinforced concrete structures affected by corrosion-in Spanish). Universidad Politécnica de Madrid (UPM), Madrid

21. Auyeung Y, Balaguru P, Chung L (2000) Bond behavior of corroded reinforcement bars. ACI Struct J 97:214-220

22. Chamberlin SJ (1956) Spacing of reinforcement in beams. Proc J Am Concr Inst 53:113-134
23. Ezeldin AS, Balaguru PN (1989) Bond behaviour of normal and high strength fibre reinforced concrete. Am Concr Inst Mater J 86:515-524

24. Fang C, Lundgren K, Chen L, Zhu C (2004) Corrosion influence on bond in reinforced concrete. Cem Concr Res 34:2159-2167. doi:10.1016/j.cemconres.2004.04.006

25. Ferguson PM, Thomson JN (1962) Development length of high strength reinforcing bars in bond. Proc J ACI 59:887-922

26. Hanjari KZ, Coronelli D (2010) Anchorage capacity of corroded reinforcement. Eccentric pull-out tests. Chalmers University of Technology, Göteborg

27. Lee HS, Noguchi T, Tomosawa F (2002) Evaluation of the bond properties between concrete and reinforcement as a function of the degree of reinforcement corrosion. Cem Concr Res 32:1313-1318. doi:10.1016/S0008-8846(02)00783-4

28. Molina M (2005) Comportamiento de estructuras de hormigón armado con una deficiente transferencia de tensiones hormigón-acero (Structural behaviour of reinforced concrete structures with a deficient transfer of stresses between concrete and steel—in Spanish). Ph.D. Thesis, Universidad Politécnica de Madrid (UPM)

29. Tang D (2007) Influence of chloride-induced corrosion cracks on the strength of reinforced concrete (Master Thesis). Master Thesis, RMIT University

30. Andrade C, Alonso C (1996) Corrosion rate monitoring in the laboratory and on-site. Constr Build Mater 10:315-328. doi:10.1016/0950-0618(95)00044-5

31. Mancini G, Tondolo F (2014) Effect of bond degradation due to corrosion-a literature survey. Struct Concr 15:408-418. doi:10.1002/suco.201300009

32. Prieto M (2014) Estudio de la adherencia de armaduras corroídas y su influencia en la capacidad resistente de elementos de hormigón armado (Study of bond with corroded steel and its influence in the resistance of reinforced concrete elements-in Spanish). Ph.D. Thesis, Universidad Politécnica de Madrid (UPM)

33. Prieto M, Tanner P, Andrade C (2014) Bond assessment of corroded steel bars in structural concrete. Paper presented at the 37th IABSE Symposium on Engineering for Progress, Nature and People, Madrid, 2014

34. IBM SPSS Statistics for Windows (2012) IBM SPSS statistics for Windows, 21 edn. IBM Corp, Armonk, NY

35. Peña D (2002) Regresión y diseño de experimentos (Regression and design of experiments-in Spanish). Alianza Editorial, Madrid

36. IETcc (2001) Contecvet manual. A validated users manual for assessing the residual service life of concrete structures. Instituto Eduardo Torroja (IETcc), Madrid. www.ietcc.csic.es

37. ACHE (2012) Monografía M-19. Modelos lineales aplicados al hormigón estructural (Linear models applied to structural concrete-in Spanish). Asociación científicotécnica del hormigón estructural (ACHE), Madrid 